\title{
Epidemiological Characteristics and Laboratory Diagnosis of Fungal Keratitis in Patients with Corneal Ulcer in Riyadh, Saudi Arabia
}

\author{
Noha Fathy Ahmed Osman El-Tahtawi \\ Department of Biology, College of Science and Humanities, Shaqra University, Al-Dawadmi, Saudi Arabia \\ Email address: \\ noha_4400@yahoo.com,N.ahmed@su.edu.sa
}

\section{To cite this article:}

Noha Fathy Ahmed Osman El-Tahtawi. Epidemiological Characteristics and Laboratory Diagnosis of Fungal Keratitis in Patients with Corneal Ulcer in Riyadh, Saudi Arabia. Clinical Medicine Research. Vol. 4, No. 6, 2015, pp. 214-220. doi: 10.11648/j.cmr.20150406.18

\begin{abstract}
Corneal blindness is a major health problem worldwide and infectious keratitis is one of the predominant causes. The incidence of fungal keratitis has increased over the last few years. Keeping this in mind, this study was conducted to evaluate the frequency of positive fungal cultures in infectious keratitis and of the various fungal species identified as etiologic agents in patients with corneal ulcer attending the ophthalmic departments of 3 hospitals in Riyadh. Corneal scrapings from 100 patients of corneal ulcer with suspected fungal etiology were subjected to direct examination by $10 \% \mathrm{KOH}$ and lactophenol cotton blue mount. Also swabs of diseased eyes were taken with sterilized swabs. The specimens were also inoculated directly on to Sabouraud's dextrose agar in C-shaped streaks. From 100 patients of corneal ulcer investigated, only 52\% of patients were positive. Males were more commonly affected than females $(69.23 \%$ and $30.76 \%)$, respectively. The age of patients was ranged from 28-55 years. 18 (34.61\%) patients with fungal keratitis were laborers, $15(28.84 \%)$ teachers, 7 $(13.46 \%)$ housewives, $6(11.53 \%)$ shepherds and $6(11.53 \%)$ were civil engineers. Corneal trauma with stone chips and metal splinters appeared to be the most common predisposing factors of fungal keratitis $(30.76 \%)$ followed by ocular surgery and corneal disease $(26.92 \%)$. Of 52 positive patients with corneal ulcer surveyed the most important causative agents of fungal keratitis were Aspergillus spp. (44.23\%), followed by Candida spp. (17.30\%) and Fusarium spp. (17.30\%). Because of serious consequences of infectious keratitis, it is important to know the exact etiology of fungal keratitis to institute appropriate therapy in time. Laboratory confirmation should be before pre scribing corticosteroids and antifungal.
\end{abstract}

Keywords: Fungal Keratitis, Corneal Ulcer, Aspergillus spp., Fusarium spp., Candida spp., Predisposing Factors

\section{Introduction}

Keratitis is an inflammation of the cornea and is often caused by bacteria, viruses and fungi. Fungal keratitis is caused by fungi and is showing inflammation of the cornea, suppurative, ulcerative, sight-threatening infection of the cornea that sometimes leads to loss of the eye. Fungal keratitis was first described by Leber in 1879 (Centers for Disease Control and Prevention, 2013; Singh, 2011).

According to the World Health Organization report, it is estimated that ocular trauma and corneal ulceration result in 1.5 to 2 million new patients of corneal blindness annually, posing a major public health problem for developing countries (Saha et al. 2009). Fungal keratitis is a major blinding eye disease in Asia and $44 \%$ of all central corneal ulcers in South India are caused by fungi (Tuladhar et al.
1988 and Sharma et al. 1993).

Fungi cannot penetrate the intact corneal epithelium and do not enter the cornea from episclerallimbal vessels. The principal routes of inoculation are introduction concurrent with a penetrating or perforating wound, either mechanical injury or surgery, and introduction through an epithelial defect (Jones, 2006).

Trauma is the major predisposing factor in healthy young males engaged in agricultural or other outdoor work. The traumatising agents can be of plant or animal origin (even dust particles), that either directly implant fungal conidia in the corneal stroma or abrade the epithelium, permitting invasion by exogenous fungi. Ocular and systemic defects, prior application of corticosteroids and prolonged use of antibiotic eye drops are also considered as predisposing factors (Insans et al. 2013).

The ocular surface is constantly exposed to a large number of 
infectious agents; however, only a few pathogens can cause a corneal infection because several mechanisms play a major role in the protection of eye surface from filamentous fungi which cause fungal corneal ulcers in humans (Insans et al. 2013).

The prevalence of individual pathogens largely depends on geographical and climatic factors. Fungal keratitis occurs mainly in the warm climates and coincides with seasonal increase in temperature and humidity (Saha and Das, 2006). More than 105 species of fungi, classified in 56 genera, have been identified as the etiological agents of fungal keratitis. Fungal keratitis can cause a deep and severe corneal ulcer. It is caused by Aspergillus spp., Fusarium spp., Candida spp., Rhizopus, Mucor, and other fungi (Thomas, 2003). Fusarium spp. and Aspergillus spp. are responsible for $70 \%$ of cases (Insans et al. 2013).

Reports from different parts of the world show that the numbers and types of ophthalmic fungi depend up on atmospheric air-spora and the presence of spore sources in the environment. Moreover, many common fungal isolates were identified as etiological agents of mycotic keratitis, and they include Aspergillus spp., Penicillium spp., Curvularia lunata, Cladosporium spp., Fusarium spp., Drechslera spicifera, Rhodotorula sp., Cylindrocarpon sp., Candida albicans, Alternaria alternata and Paecilomyce spp. Identification and diagnosis of these fungi by wide range of conventional and molecular techniques are currently available. Early diagnosis and appropriate treatment are essential to control the disease and avoiding blindness (Alqurashi, 2009).

This study was conducted to evaluate the frequency of positive fungal cultures in infectious keratitis, epidemiology of fungal keratitis and of the various fungal species identified as etiologic agents in patients suffering from fungal keratitis admitted to ophthalmology department, in different three hospitals in Riyadh.

\section{Materials and Methods}

\subsection{Patients}

100 patients (53 males and 47 females) of clinically suspected mycotic corneal ulcers admitted to ophthalmology department, in different three hospitals in Riyadh during the period of February 2013 to October 2013 (9 months), were subjected to this study. A detailed history of present illness was undertaken on all patients with special reference to age, occupation, trauma, medication to eye and surgical intervention, systemic diseases, and use of cosmetic or therapeutic contact lenses.

\subsection{Methods}

In all cases, corneal scrapings were aseptically collected directly from the base and margins of ulcers using with a tip of a disposable 23-gaugeneedle, after instillation of topical anesthetic ( $0.5 \%$ tetracaine). Direct microscopy was done under $10 \% \mathrm{KOH}$ examination and lactophenol cotton blue mount. Also a sterile Dacron swab was used to obtain a corneal scrape from the base and leading edge of the corneal ulcer.

\subsubsection{Culturing on Sabouraud's Dextrose Agar (SDA)}

The specimens were cultured onto Sabouraud's Dextrose agar (SDA) (HiMedia, Mumbai, India) plates supplemented with $0.05 \%(\mathrm{~W} / \mathrm{V})$ chloramphenicol in the form of $\mathrm{C}$ streaks; only growth occurring on the $\mathrm{C}$ streaks was considered to be significant. All the media were incubated at $37^{\circ} \mathrm{C}$ and $25^{\circ} \mathrm{C}$ for a period of four weeks. Although fungal growth is usually seen within three to four days, negative culture media may require incubation for up to four weeks. Cultures were checked every day during the first week and twice a week for the next three weeks. Any growth present on the medium was identified by standard laboratory techniques viz. the rate of growth, colony morphology, and microscopic appearances in lactophenol cotton blue mount and slide culture.

\subsubsection{Culturing on CHROMagar Candida Media}

Chromogenic media contain chromogenic substrates which react with enzymes secreted by the target microorganisms to yield colonies of varying colures (Pfaller et al. 1996). CHROMagar Candida Differential agar (CHROMagar Company, Paris, France) is a selective and differential medium, which facilitates rapid isolation and presumptive identification of some yeasts from mixed cultures. The medium contained $(\mathrm{g} / \mathrm{L})$ : agar 15; peptone 10.2; chromogenic mix 22; chloramphenicol $0.5 ; \mathrm{pH}: 6.1$. According to the manufacturer 47.7 grams of the powdered medium were slowly dispersed in 1 liter of sterile distilled water and brought to a boil by repeated heating until complete fusion of agar grains. The medium was cooled in a water bath to $45-$ $50^{\circ} \mathrm{C}$, with gentle stirring, then poured into sterile petri dishes and allowed to solidify. Separate colonies from all Candida isolates on SDA were subcultured onto CHROMagar Candida and incubated at $37^{\circ} \mathrm{C}$ for $48 \mathrm{hr}$. Presumptive identification was done based on colony colour of the growing Candida strains. According to the manufacturer, $C$. albicans appears as green colored smooth colonies, C. tropicalis appears as metallic blue, C. krusei appears as pink fuzzy colonies, $C$. glabrata appears as mauve dark pink and $C$. parapsilosis appears as white pale pink.

\section{Results}

Out of 100 cases of corneal ulcer investigated, mycotic infection was observed in $52(52 \%)$ patients. A total of 52 patients met the inclusion criteria of this study, of whom 36 $(69.23 \%)$ were males and $16(30.76 \%)$ were females. The age of patients was ranged from 28 - 55 years. Eighteen $(34.61 \%)$ patients with fungal keratitis were laborers, fifteen $(28.84 \%)$ teachers, seven $(13.46 \%)$ housewives, six (11.53\%) shepherds and six $(11.53 \%)$ were civil engineers. (Table1 \& 2, Fig. $1 \& 2$ ).

\subsection{Predisposing Factors}

Corneal trauma with stone chips and metal splinters 
appeared to be the most common predisposing factors in our study as it were observed in $16(30.76 \%)$ patients with fungal keratitis, followed by ocular surgery and corneal disease that were recorded as predisposing factors in 14 cases (26.92\%).Eight patients $(15.38 \%)$ received topical antibiotics and corticosteroid. Seven patients (13.46\%) had diabetes and also seven patients had a history of using contact lenses. (Table 2, Fig. 3)

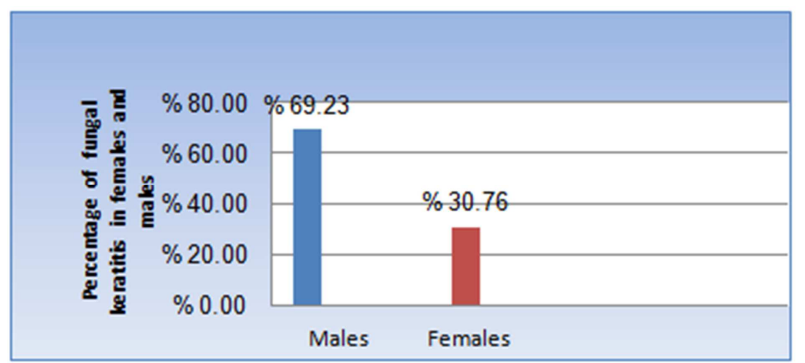

Fig. 1. Distribution of fungal keratitis between male and female patients.

Table 1. Epidemiology of fungal Keratitis and identification after phenotyping

\begin{tabular}{|c|c|c|c|c|c|}
\hline Case No. & $\begin{array}{l}\text { Age in } \\
\text { years }\end{array}$ & Gender & Occupation & Risk factors & $\begin{array}{l}\text { Identification of fungi by } \\
\text { phenotypic characters }\end{array}$ \\
\hline 1 & 50 & Male & Shepherds & Corneal trauma (Animal's tails) & Aspergillus flavus \\
\hline 2 & 30 & Female & Housewife & Diabetes & Aspergillus niger \\
\hline 3 & 35 & Male & Laborer & Topical antibiotics & Fusarium solani \\
\hline 4 & 50 & Male & Laborer & Corneal trauma(Metal splinters) & Mucor spp \\
\hline 5 & 55 & Male & laborer & Ocular surgery & Aspergillus flavus \\
\hline 6 & 34 & Female & Housewife & Diabetes & Candida albicans \\
\hline 8 & 32 & Female & Teacher & Ocular surgery & Aspergillus flavus \\
\hline 9 & 40 & Male & Shepherds & Corneal trauma (Stone chips) & Candida glabrata \\
\hline 10 & 43 & Female & Teacher & Use of contact lens & Aspergillus terreus \\
\hline 11 & 31 & Male & Teacher & Topical antibiotics & Curvularia lunata \\
\hline 12 & 33 & Female & Housewife & Use of contact lens & Fusarium solani \\
\hline 13 & 36 & Male & laborer & Topical antibiotics & Mucor spp. \\
\hline 14 & 43 & Male & Teacher & Topical antibiotics & Aspergillus terreus \\
\hline 17 & 47 & Male & Civil Engineer & Corneal trauma (Stone chips) & Aspergillus terreus \\
\hline 18 & 30 & Male & Civil Engineer & Use of topical corticosteroid & Candida glabrata \\
\hline 19 & 37 & Female & Teacher & Use of contact lens & Acremonium species \\
\hline 20 & 40 & Female & Teacher & Use of contact lens & Aspergillus flavus \\
\hline 21 & 43 & Male & Teacher & Topical antibiotics & Aspergillus fumigates \\
\hline 22 & 34 & Male & Teacher & Diabetes & Aspergillus terreus \\
\hline 23 & 35 & Male & laborer & Corneal trauma (Stone chips) & Curvularia lunata \\
\hline 24 & 36 & Male & laborer & Corneal disease (Persistent corneal defect and stromal ulceration) & Aspergillus flavus \\
\hline 25 & 42 & Female & Housewife & Use of contact lens & Aspergillus terreus \\
\hline 26 & 43 & Female & Teacher & Ocular surgery & Alternaria alternata \\
\hline 27 & 44 & Male & laborer & Diabetes & Fusarium solani \\
\hline 28 & 29 & Male & laborer & Corneal disease (Persistent corneal defect and stromal ulceration) & Fusarium solani \\
\hline
\end{tabular}

Table 1. Continued.

\begin{tabular}{|c|c|c|c|c|c|}
\hline Case No. & Age in years & Gender & Occupation & Risk factors & $\begin{array}{l}\text { Identification of fungi by } \\
\text { phenotypic characters }\end{array}$ \\
\hline 29 & 39 & Male & Laborer & Corneal trauma(Metal splinters) & Penicillium spp. \\
\hline 30 & 45 & Female & Housewife & Diabetes & Aspergillus fumigatus \\
\hline 31 & 32 & Male & Shepherds & Corneal trauma (Stone chips) & Aspergillus niger \\
\hline 32 & 33 & Male & $\begin{array}{l}\text { Civil } \\
\text { Engineer }\end{array}$ & Corneal trauma (Stone chips) & Fusarium solani \\
\hline 33 & 35 & Male & Laborer & $\begin{array}{l}\text { Corneal disease (Persistent corneal defect and stromal } \\
\text { ulceration). }\end{array}$ & Aspergillus flavus \\
\hline 34 & 36 & Male & Laborer & Corneal trauma(Metal splinters) & Candida krusei \\
\hline 35 & 52 & Male & $\begin{array}{l}\text { Civil } \\
\text { Engineer }\end{array}$ & Corneal trauma (Stone chips) & Aspergillus flavus \\
\hline 36 & 40 & Male & Shepherds & Corneal trauma (Animal's tails) & Candida krusei \\
\hline 37 & 42 & Female & Teacher & Use of contact lens & Fusarium solani \\
\hline 38 & 43 & Female & Teacher & Use of contact lens & Candida albicans \\
\hline 39 & 45 & Male & $\begin{array}{l}\text { Civil } \\
\text { Engineer }\end{array}$ & Corneal trauma (Stone chips) & Aspergillus fumigatus \\
\hline 40 & 34 & Male & Laborer & Diabetes & Rhizopus spp. \\
\hline 41 & 35 & Male & Teacher & Ocular surgery & Candida krusei \\
\hline 42 & 37 & Male & Laborer & Ocular surgery & Aspergillus flavus \\
\hline
\end{tabular}




\begin{tabular}{|c|c|c|c|c|c|}
\hline Case No. & Age in years & Gender & Occupation & Risk factors & $\begin{array}{l}\text { Identification of fungi by } \\
\text { phenotypic characters }\end{array}$ \\
\hline 43 & 38 & Female & Teacher & Ocular surgery & Aspergillus niger \\
\hline 44 & 39 & Male & Laborer & Diabetes & Fusarium solani \\
\hline 45 & 40 & Female & Housewife & Ocular surgery & Aspergillus flavus \\
\hline 46 & 42 & Male & Teacher & Use of topical corticosteroid & Candida albicans \\
\hline 47 & 41 & Male & Shepherds & Corneal trauma (Animal's tails) & Candida glabrata \\
\hline 48 & 43 & Male & $\begin{array}{l}\text { Civil } \\
\text { Engineer }\end{array}$ & Ocular surgery & Aspergillus fumigatus \\
\hline 49 & 44 & Male & Laborer & Corneal trauma (Stone chips) & Aspergillus terrues \\
\hline 50 & 50 & Female & Teacher & $\begin{array}{l}\text { Corneal disease (Persistent corneal defect and stromal } \\
\text { ulceration). }\end{array}$ & Fusarium solani \\
\hline 51 & 30 & Male & Shepherds & Corneal trauma (Animal's tails) & Alternaria alternata \\
\hline 52 & 33 & Male & Laborer & Ocular surgery & Aspergillus flavus \\
\hline
\end{tabular}

Table 2. Summary of cases of fungal keratitis and percentage.

\begin{tabular}{lll}
\hline Criteria & Number & Number (\%) \\
\hline Gender & Total =52 & $52 \%$ \\
Male & 36 & $69.23 \%$ \\
Female & 16 & $30.76 \%$ \\
Occupation & & \\
Shepherds & 6 & $11.53 \%$ \\
Housewife & 7 & $13.46 \%$ \\
Laborer & 18 & $34.61 \%$ \\
Teacher & 15 & $28.84 \%$ \\
Civil Engineer & 6 & $11.53 \%$ \\
Risk factors & & \\
Corneal trauma & 16 & $30.76 \%$ \\
Topical antibiotic/Corticosteroid & 8 & $15.38 \%$ \\
Use of contact lens & 7 & $13.46 \%$ \\
Ocular Surgery/Corneal disease & 14 & $26.92 \%$ \\
Systemic diseases(Diabetes) & 7 & $13.46 \%$ \\
\hline
\end{tabular}

Incidence of fungal keratits.

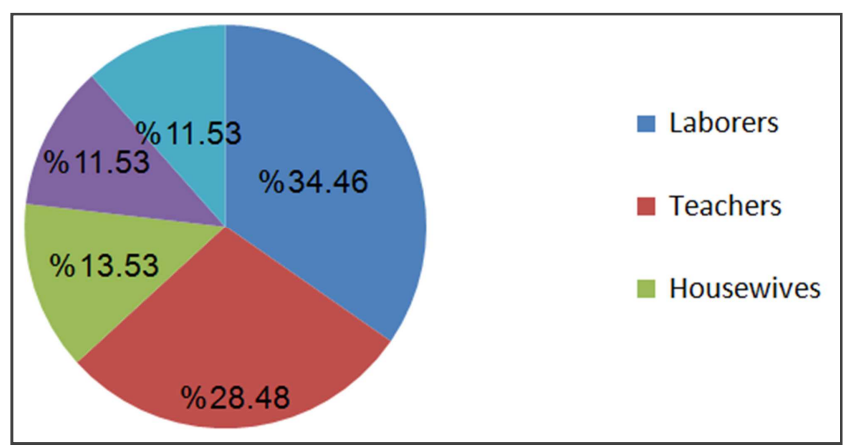

Fig. 2. Percentage of fungal Keratitis in patients according to their occupation.

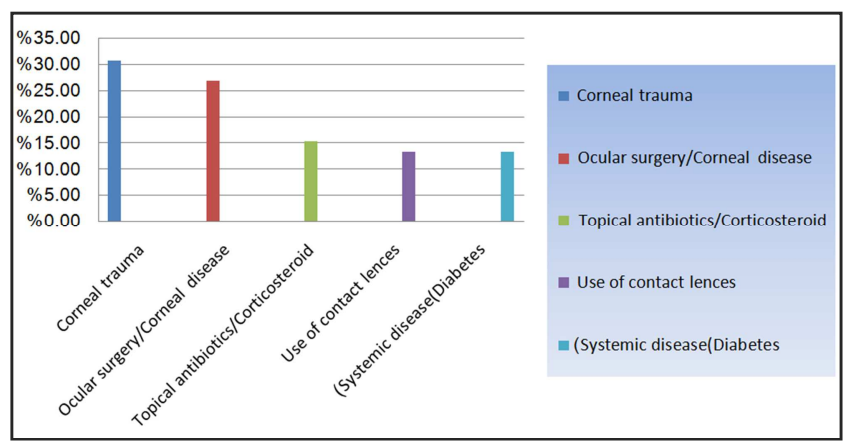

Fig. 3. Percentage incidence of fungal Keratits according to different predisposing factors.

\subsection{Etiological Factors}

Of 52 positive patients with corneal ulcer surveyed during the period of February 2013 to October 2013 (9 months), the most important causative agents of fungal keratitis were Aspergillus spp. with frequency $(44.23 \%)$, followed by Candida spp. (17.30\%) and Fusarium spp. (17.30\%). Alternaria alternate, Mucor spp., Curvularia lunata, Acremonium spp., Rhizopus spp. Penicillium spp. and Rhodotorula spp. were also detected in positive cases but in low frequency ranged from $(5.76 \%-1.9 \%)$.Aspergillus flavus (19.23\%), Fusarium solani (17.30\%) and Aspergillus terreus $(11.53 \%)$ were the predominant etiologic agents of corneal ulceration (Table 3).

Table 3. Etiological agents of fungal keratitis.

\begin{tabular}{lll}
\hline Fungi & Number & Number \% \\
\hline Aspergillus spp. & Total 23 & $44.23 \%$ \\
Aspergillus flavus & 10 & $19.23 \%$ \\
Aspergillus fumigatus & 4 & $7.69 \%$ \\
Aspergillus terreus & 6 & $11.53 \%$ \\
Aspergillus niger & 3 & $5.76 \%$ \\
Candida spp. & Total 9 & $17.30 \%$ \\
Candida albicans & 3 & $5.76 \%$ \\
Candida glabrata & 3 & $5.76 \%$ \\
Candida krusei & 3 & $5.76 \%$ \\
Fusarium solani & 9 & $17.30 \%$ \\
Alternaria alternata & 3 & $5.76 \%$ \\
Mucor spp. & 2 & $3.84 \%$ \\
Curvularia lunata & 2 & $3.84 \%$ \\
Acremonium spp. & 1 & $1.9 \%$ \\
Rhizopus spp. & 1 & $1.9 \%$ \\
Rhodotorula spp. & 1 & $1.9 \%$ \\
Penicillium spp. & 1 & $1.9 \%$ \\
\hline
\end{tabular}

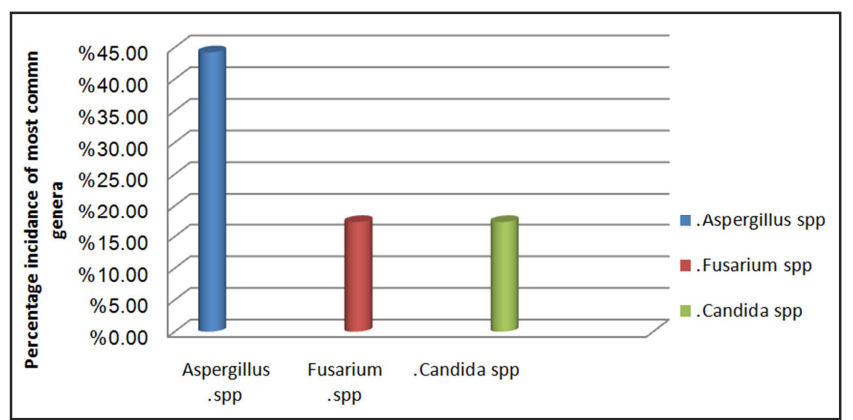

Fig. 4. Percentage incidence of most common genera. 


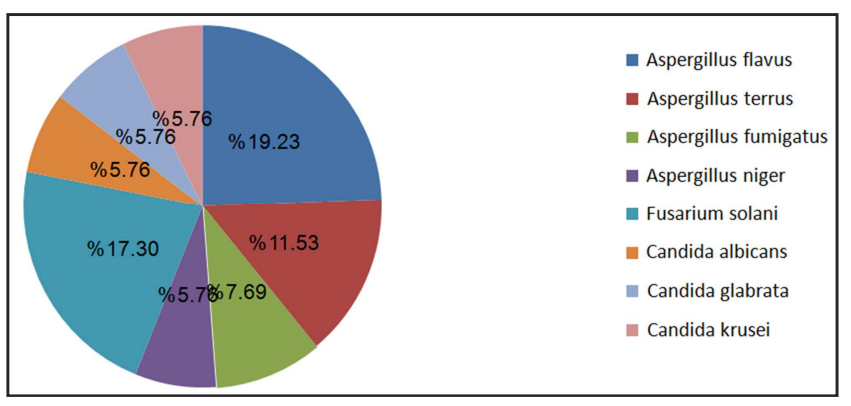

Fig. 5. Percentage incidence of most common etiologic agents.

\section{Discussion}

Mycotic keratitis is an important ophthalmic problem in all parts of the world, because it leads to corneal blindness and sometimes in loss of the eye. Various published reports indicate that mycotic keratitis account for $6 \%$ to $50 \%$ of all cases of ulcerative keratitis (Rosa, et al. 1994; Upadryay, et al. 1991 and Dunlop et al. 1994). In this study the percent of ulcerative keratitis was $52 \%$. Males were significantly more frequently affected than females $(69.23 \%$ and $30.76 \%$, respectively). Fungal corneal ulcers may be reported at any age and in the present study, the age of the patients varied from 28 to 55 years. These results are nearly similar to those reported by Gopinathan et al. (2002) who found that the males were significantly more frequently affected than females (a ratio of 2.5:1). Also Kalshetti et al.(2015) found that from 40 patients only $24(60 \%)$ were males and $16(40 \%)$ were females. $64 \%$ of patients were in the age group 20 to 50 years (Tilak etal. 2009) whereas the highest prevalence rate of fungal keratitis was identified in the patients with $40-90$ years age group according to Haghani et al.(2015).Chowdhary and Singh (2005) found that men $(68 \%)$ were more commonly affected by fungal keratitis than women (32\%). Also, Xie et al. (2006) found that fungal keratitis was more common in males $(60.6 \%)$ than in females $(39.4 \%)$. On the other hand, the results which were recorded by El-Sayed et al. (2010) revealed that fungal keratitis was more common in female $(75 \%)$ than in male patients $(25 \%)$.

In our study $(34.61 \%)$ patients with fungal keratitis were laborers, $(28.8 \%)$ teachers, $(13.46 \%)$ housewives, (11.53\%) shepherds and $(11.53 \%)$ were civil engineer. Previous report recorded $(42.9 \%)$ patients with fungal keratitis were farmers; one $(14.3 \%)$ animal husbandman, one (14.3\%) laborer, and 2 (28.6\%) were housewives (Shokohiet al.1999). Kalshetti et al. (2015) reported that seven (50\%) patients with fungal keratitis were farmers, three (21.4\%) laborer and four $(28.5 \%)$ were housewives.

Corneal trauma has been identified as the most common risk factor for mycotic keratitis, which was also the case in the present study. Stone chips and metal splinters were reported to be the most frequent traumatising agent in our series (16 cases). Other predisposing risk factors were ocular surgery and corneal diseases which were detected in 14 cases. Topical antibiotic/Corticosteroidusage in eight cases. Six cases gave the history of using contact lens and other six cases were diabetics. Results which were recorded by ElSayed et al. (2010) revealed that the most common risk factors for fungal keratitis were contact lens use $(50 \%)$, corneal trauma $(50 \%)$, using of topical steroid (25\%) and diabetes mellitus (25\%).

Tilak et al. (2010) reported that plant material was to be the most frequent traumatising agent followed by chronic antibiotic / topical corticosteroids usage in nine cases. Six cases gave the history of cataract surgery but history of the use of contact lenses was not found in any case. Shokohi et al. 2006 found that $28.6 \%$ of patients with fungal keratitis had corneal trauma, which is lower than that reported for fungal keratitis in general. A frequency of $33 \%$ to $100 \%$ has been described in the literature for mycotic keratitis in patients with corneal trauma by things having organic material or foreign body (Rosa, et al. 1994; Alfonso, et al. 1997 and Liesegang, et al. 1980). In some other reports, $8.3 \%$ to $17.6 \%$ of patients with fungal keratitis had corneal trauma, which is lower than our report. The fewer number of patients with fungal keratitis and corneal trauma could be explained by the fact that trauma might be insensible or as a result of delay existing between the occurrence of trauma and its diagnosis, causing them difficult to recall. (Shokohi et al. 2006).

In this study, the majority of fungal keratitis was due to Aspergillus spp. with frequency (44.23\%), followed by Candida spp. (17.30\%) and Fusarium spp. (17.30\%). Nearly similar to results which were reported by Saha et al. (2009) whereas, Aspergillus species (55.4\%) and Candida species $(18.91 \%)$ were found to be the major etiologic agents of fungal keratitis followed by Fusarium $s p$. (10.81\%).

Chander et al. (2008) reported that the most common fungal isolates were Aspergillus spp. (41.18\%), Fusarium spp. (23.53\%), Candida spp. (8.82\%), Curvularia spp. (5.88\%), and Bipolaris spp. (5.88\%), while Gopinathan et al. (2009) found that Fusarium spp. were the most common fungal pathogen accounting for $36.6 \%$ of cases of fungal keratitis. And also Mohd-Tahier et al. (2012) recorded that Fusarium species $(46.34 \%, 19 / 41)$ were the most common fungal isolated, followed by Candida species (12.20\%, 5/41). Aspergillus species (06) and Fusarium species (05) were the major isolates in the study of Kalshetti et al. (2015). Filamentous fungi were isolated in $85.7 \%$ cases of fungal keratitis. Aspergillus flavus, Fusarium species and Candida glabrata were isolated from patient's samples.

Aspergillus flavus was the most prevalent species. (Haghani et al. 2015).

Our results are not supported by data mentioned by Bhartiya et al. (2007) who reported that Candida albicans $(37.2 \%)$ was the main cause of fungal keratitis in Mellbourne, Australia, followed by Aspergillus fumigates (17.1\%), and Fusarium (14.3\%). Also, similar results were obtained by Rondeau et al. (2002). Sun et al.(2007) reported that Candida albicans was the most common Candida spp. isolated from cases of Candida keratitis, accounting for $69 \%$ of cases. Also, Tanure et al. (2000) mentioned that Candida albicans was found to be the most commonly isolated organism (45.8\%), followed by Fusarium spp. (25\%). 


\section{Conclusion}

Indeed, the incidence of fungal keratitis has increased dramatically over the past 30 years, with some authors reporting up to $17-44 \%$ of keratitis cases caused by fungi. The key element in the diagnosis of fungal keratitis is the clinical suspicion by ophthalmologists. Fungal corneal ulcer is common in Asia due to the tropical climate and a large population that is at risk. Various factors are involved, such as trauma and the injudicious use of topical antibiotics and corticosteroids. However, due to the potential serious complications from fungal keratitis, it is important to know the exact etiology of corneal ulcer to institute appropriate therapy in time.

\section{References}

[1] Alqurashi, M. A. (2009): Survey of opportunistic fungi in ocular infection in the Eastern Province of Saudi Arabia. Journal of Food, Agriculture \& Environment Vol. 7(2): 247251. 2009.

[2] Bhartiya, P., Daniell, M., Constantinou, M., Islam, F. M., and Taylor, H. R. (2007): Fungal keratitis in Melbourne. Clin Experiment Ophthalmol; 35(2): 124-130.

[3] Centers for Disease Control and Prevention. 2013: Atlanta, USA: Fungal keratitis [updated 2013 may 6]. Available from: http://www.cdc.gov/fungal/ fungal-keratitis/definition.html.

[4] Chander, J., Singla, N., Agnihotri, N., Arya, S. K., and Deep, $A$. (2008): Keratomycosis in and around Chandigarh: a fiveyear study from a north Indian tertiarycare hospital. Indian J Pathol Microbiol; 51(2): 304-306.

[5] Chowdhary, A., and Singh, K. (2005). Spectrum of fungal keratitis in North India. Cornea; 24(1): 8-15.

[6] Dunlop AA, Wright ED, Howlader SA, Nazrul I, Husain. R, McClellan $K$, et al. Suppurative corneal ulceration in Bangladesh. A study of 142 cases examining the microbiological diagnosis, clinical diagnosis, and epidemiological features of bacterial and fungal keratitis. Aust N Z J Ophthalmol. 1994; 22: 105-110.

[7] El-Sayed, O. A.; Othman, T. A.; El-Morsy, F. E.: Hassan, A. M. and Mohamed, S. T. (2010): Mycotic Eye Infections in Ophthalmic Center, Mansoura University. Egyptian Journal of Medical Microbiology, January 2010 Vol. 19, No. 1.

[8] Gopinathan, U., Sharma, S., Garg, P., and Rao, G. N. (2009). Review of epidemiological features, microbiological diagnosis and treatment outcome of microbial keratitis: experience of over a decade. Indian J Ophthalmol; 57(4): 273-279.

[9] Gopinathan $U$, Garg $P$, Fernandes $M$, Sharma $S$, Athmanathan $S$, Rao GN (2002): The epidemiological features and laboratory results of fungal keratitis: a 10-year review at a referral eye care center in south India. Cornea 21: 555-59.

[10] Haghani, I., Amirinia, F., Nowroozpoor-Dailami, K. and Shokohi T. (2015): Detection of fungi by conventional methods and semi-nested PCR in patients with presumed fungal keratitis. Curr Med Mycol, 2015 Jun, 1 (2): 31-38.
[11] Insans, N. G.; Chaudhart, B. L.; Danu, M. S.; Yadav, A. and Srivastava, V. (2013): Areview of fungal Keratits: etiology and Laboratory diagnosis. Int. J. Curr. Microbiol. App. Sci (2013) 2(6): 307-314

[12] Jones, D. B., 2006. Duane, s Ophthalmology: Diagnosis and Management of Fungal Keratitis. Philadelphia: Lippincott Williams \&Wilkins.

[13] Kalshetti, V. T., Wadgaonkar, S. P., Bhate, V. M., Wadile, R. G., Haswani, N. and Bothikar, S. T. (2015): Microbiological evaluation of mycotic keratitis in north Maharashtra, India: A prospective study. Journal of Microbiology and Infectious Diseases; 5 (3): 99-102

[14] Mohd-Tahier, F.; Norhayati, A.; Siti-Raihan, I. and Ibrahim, M. (2012): A 5-Year Retrospective Review of Fungal Keratitis at Hospital Universiti Sains Malaysia. Interdisciplinary Perspectives on Infectious Diseases Volume 2012 (2012), Article ID 851563, 6 pages doi: $10.1155 / 2012 / 851563$.

[15] Pfaller, MA.; Houston, A. and Coffmann S. Application of CHRO Magar Candida for rapid screening of clinical specimens for Candida. albicans, Candida tropicalis, Candida krusei, and (Torulopsis) glabrata. JClinMicrobiol; 1996; 34: 58-61.

[16] Rondeau, N., Bourcier, T., Chaumeil, C., Borderie, V., Touzeau, O., Scat, Y., Thomas, F., Baudouin, C., Nordmann, J. P., and Laroche, L. (2002). Fungal keratitis at the Centre Hospitalier National d'Ophtalmologie des Quinze-Vingts: retrospective study of 19 cases. J FrOphtalmol; 25(9): 890896.

[17] Rosa RH Jr, Miller D, Alfonso EC. The changing spectrum of fungal keratitis in South Florida. Ophthalmology. 1994; 101: 1005-1013.

[18] Saha, S., D. Banerjee and Sengupta J. 2009: Epidemiological profile offungal keratitis in urban population of West Bengal, India. Oman. J. Ophthalmol. 2(3): 114-118.

[19] Saha, R., and Das, S. (2006): Mycological profile of infectious Keratitis from Delhi.Indian J Med Res; 123(2): 159164.

[20] Sharma S, Srinivasan M, George C: Thecurrent status of Fusarium species in mycotic keratitis in South India. J Med Microbiol 1993, 11: 140-147.

[21] Shokohi T. Mycotic Keratitis (case report).J Med Facul GuilanUniv Med Sci. 1999; 13: 61-66.

[22] Shokokkohi, T.; Dailami, K. N. and Haghighi, T. M. (2006): FUNGAL KERATITIS IN PATIENTS WITH CORNEALULCER IN SARI, NORTHERN IRAN. Arch Iranian Med 2006; 9 (3): 222-227.

[23] Singh, D.. 2011: Medscape Drugs, Disease and Procedure. New York: Fungalkeratitis (Updated 2011 Oct 27).Available from: http://emedicine.medscape.com/article/1194167overview.

[24] Sun, R. L., Jones, D. B., and Wilhelmus, K. R. (2007: Clinical characteristics and outcome of Candida keratitis. Am J Ophthalmol; 143(6): 1043-1045.

[25] Thomas PA (2003): Fungal infection of the cornea. Eye 17: 852-862. 
[26] Tanure, M. A., Cohen, E. J., Grewal, S., Rapuano, C. J., and Laibson, P. R. (2000): Spectrum of fungal keratitis at Wills Eye Hospital, Philadelphia, Pennsylvania. Cornea; 19: 307312 .

[27] Tilak, R.; Singh, A.; Maurya, O. P. S.; Ghandraa, A.; Tilak, V. and Gulati, K. A. (2009): Mycotic keratitis in India: a five-year retrospective study. J Infect Dev Ctries 2010; 4(3): 171-174.

[28] Upadhay MP. Karmacharya PCD, KoiralaS, TuladharNR. Bryan LL Smolin $D$ et al. Epidemiologic characteristics, predisposing factors and etiological diagnosis of corneal ulceration in Nepal. Am J Ophthalmo/1988; 106: 92-99.

[29] Upadhyay MP, Karmacharya PC, Koirala S, Tuladhar NR, Bryan LE, Smolin $G$, et al. Epidemiologic characteristics, predisposing factors, and etiologic diagnosis of corneal ulceration in Nepal. Am J Ophthalmol. 1991; 111: 92 - 99.

[30] Xie, L., Zhong, W., Shi, W., and Sun, S. (2006): Spectrum of fungal keratitis in north China. Ophthalmology; 113(11): 1943-1948. 